\title{
Noise attenuation provided by hedges
}

\author{
Marcello Biocca, Pietro Gallo, Giuseppina Di Loreto, Giancarlo Imperi, Daniele Pochi, Laura Fornaciari \\ Consiglio per la ricerca in agricoltura e l'analisi dell'economia agraria (CREA), Centro di ricerca Ingegneria e \\ Trasformazioni agroalimentari, Monterotondo (RM) Italy
}

\begin{abstract}
During the past few decades, urban areas have experienced increasing environmental stress. Noise is considered as one of the most important sources of urban pollution with adverse effects on human health. Urban vegetation provides many ecosystem services including the reduction of noise pollution. Hedges are widespread in cities and have the peculiarity of being often grown close to the source of noise. The study investigated the noise reduction due to hedges of Prunus laurocerasus and Laurus nobilis and the effect of the vegetation on sound spectra. Four different trials were carried out, including the use of two different noise sources and the measurement of noise at different distances both from the green barrier and from the noise source. During one trial, the influence of the type of ground surfaces between the noise source and the receiver was also evaluated. In the three trials where a significant attenuation of the noise occurred, the porosity of hedges measured less than $4.6 \%$ and an average noise reduction of about $2.7 \mathrm{~dB}(\mathrm{~A})(\max 7.0 \mathrm{~dB}(\mathrm{~A}))$ was observed. This effect was particularly relevant in the range of higher frequencies (between 2 and $20 \mathrm{kHz}$ ). This study can contribute to plan and design hedges in the urban context.
\end{abstract}

Correspondence: Marcello Biocca, Consiglio per la ricerca in agricoltura e l'analisi dell'economia agraria (CREA), Centro di ricerca Ingegneria e Trasformazioni agroalimentari (Research Centre for Engineering and Agro-Food Processing), via della Pascolare 16, 00015 Monterotondo (RM) Italy.

Tel.: +39.06.90675215.

E-mail: marcello.biocca@crea.gov.it

Key words: Noise barriers; noise pollution; vegetation belts; Laurus nobilis; Prunus laurocerasus.

Funding: this research was funded by the Italian national project URBANFOR3, funded by Lazio Innova (CUP: C82I16000000005).

Contributions: the authors contributed equally.

Conflict of interests: the authors declare no potential conflict of interests.

Received for publication: 17 July 2018.

Accepted for publication: 3 July 2019.

(C) Copyright: the Author(s), 2019

Licensee PAGEPress, Italy

Journal of Agricultural Engineering 2019; L:889

doi:10.4081/jae.2019.889

This article is distributed under the terms of the Creative Commons Attribution Noncommercial License (by-nc 4.0) which permits any noncommercial use, distribution, and reproduction in any medium, provided the original author(s) and source are credited.

\section{Introduction}

Noise pollution is a major environmental health concern. In Europe, the road traffic remains the dominant source affecting human exposure above the EU's threshold of 55 decibels $(\mathrm{dB})$ for daily exposure and of $50 \mathrm{~dB}$ for night exposure. Around 100 million people are exposed to road traffic noise above $55 \mathrm{~dB}$ in 33 European countries. Of these, 32 million are exposed to very high noise levels (above $65 \mathrm{~dB}$ ). The harmful effects of noise arise mainly from the stress reaction it causes in the human body. These can potentially lead to premature death, cardiovascular disease, cognitive impairment, sleep disturbance, hypertension and, at the least, annoyance (EEA, 2017).

Urban vegetation provides many significant ecological and environmental benefits to ameliorate the quality of life in towns. For example, plants reduce the urban heat island effect (Bowler et al., 2010), increase biodiversity (Alvey, 2006), ameliorate the microclimate (Federer, 1976; Escobedo et al., 2011), reduce airborne particulate matter (Mori et al., 2015), uptake and store atmospheric $\mathrm{CO}_{2}$ and other gaseous pollutants (Nowak et al., 2006), reduce storm water runoff, thus reducing the likelihood of flooding (Bolund and Hunhammar, 1999) and can provide improvements in the rehabilitation of psychiatric patients (Erbino et al., 2015)

Urban vegetation has also been reported for its noise barrier effect, resulting from a combination of physical and psychological factors (Viollon et al., 2002; Yang et al., 2011; Van Renterghem et al., 2012; Van Renterghem, 2018).

Given the high variability of green barriers in terms of density, species and size, their effectiveness and capability in reducing noise levels are still being debated. For example, Kragh (1981) measured a maximum attenuation of $5 \mathrm{~dB}$ through $3 \mathrm{~m}$ of dense conifers. Fang and Ling (2003), studied many evergreen-tree belts and found a group of species which can effectively reduce noise, with values of excess attenuation greater than $6 \mathrm{~dB}(\mathrm{~A})$. The same authors (2005) underlined the importance of various morphology features of the tree belts in reducing the noise. Ow and Ghosh (2017) found that vegetative barriers (moderate to dense) were able to reduce traffic noise by $9-11 \mathrm{~dB}$ on average, while Van Renterghem and coauthors (2014) stated that thick dense hedges are found to provide only a small reduction of total A-weighted noise from light vehicle at low speeds, with measured insertion losses range from $1.1 \mathrm{~dB}(\mathrm{~A})$ to $3.6 \mathrm{~dB}(\mathrm{~A})$. In a study on the vegetation of the city of Rome, Gratani and Varone (2013) observed that the maximum noise attenuation caused by hedges was around $13 \%$. A study by Maleki and coauthors (2010) reported that mixed stands had the best effect on noise pollution reduction, which was about $16.91 \mathrm{~dB}(\mathrm{~A})$. Noise level reduction was also achieved up to $17 \mathrm{~dB}$ when compared to the open area (Islam et al., 2012). Vegetation added on a earth mound close to a highway increased noise attenuation of about 2-3 dB(A) (Ciammaichella et al., 2005).

The various green infrastructures present in towns (trees, 
hedges, lawns and green roofs) differently contribute to noise reduction. In general, hedges are less effective than artificial barrier. However, hedges (or hedgerows) present several advantages. For example, they can be easily planted near noise source (resulting more effective in noise reduction than the barriers installed near the noise receivers - Bucur, 2006), they perform various ecological, visual and aesthetic services and can be realised using a wide variety of species.

The aim of this paper was to investigate the contribution of hedges to the attenuation of the noise generated in a real-life situation. The study concerned evergreen hedges of different sizes formed by Laurel (Laurus nobilis L., grown in containers) or Cherry Laurel (Prunus laurocerasus L.), species widespread in Mediterranean cities, but poorly studied with regard to their aptitude to reduce noise.

\section{Materials and methods}

Table 1 reports a basic description of the performed trials. To create barriers of different depths, Laurel plants grown in containers $(0.25 \mathrm{~m}$ in diameter) were arranged in $1,2,3$ and 4 rows, obtaining (mobile) hedges measuring a width of $0.40,0.85,1.20$ and $1.65 \mathrm{~m}$, respectively. Two other sets of measurements (trials T2 and T3) were carried out using a natural Cherry Laurel hedge grown between a parking area in asphalt and a country road in gravel. This hedge was tested before and after a pruning, that reduced its width of about $0.7 \mathrm{~m}$. All hedges were $7.5 \mathrm{~m}$ long.

To obtain a common indicator to describe the depth and thickness of the vegetation, the hedges were characterised for their optical porosity, a parameter based on the visibility through the vegetation, assumed as a surrogate of the vegetation density (Fang and Ling, 2003). Optical porosity value can range from $0 \%$ (maximum density of the vegetation, i.e. hedge completely opaque, objects behind the hedge are not visible) to $100 \%$ (completely transparent). Optical porosity was determined by image analysis of digital pictures of the canopy taken before each noise measurement. The pictures were firstly elaborated to get an 8-bit black and white image, then analysed by means of a specific procedure of the software ImageJ (Schneider et al., 2012), to obtain the percentage of visible background.

\section{Noise sources}

During the trials, two different sources of noise, with different pressure levels and spectra of sound, were employed. The first source was a used hand-held brush cutter (Efco, model 8460) powered by a two-stroke engine of $45.7 \mathrm{~cm}^{3}$, operating at the maximum speed $\left(11,700 \mathrm{rev} \mathrm{min}^{-1}\right)$. The second source was the central unit of an air conditioning plant (RC Group s.p.a., model 204 P2 D VT2) located in the garden besides the main building of the Research Centre for Engineering and Agro-Food Processing (approximately $42^{\circ} 5,51.26 ” \mathrm{~N} ; 12^{\circ} 37^{\prime} 3.52$ ” E).

\section{Acoustic measurements}

The following instruments were used for the measurement of noise: i) signal acquisition and data processing portable system "Soundbook" (SINUS Messtechnik GmbH) with special software "Samurai"; ii) microphone Brüel \& Kjær, mod. 4189, class 1, with windscreen; iii) microphone calibrator Brüel \& Kjær, mod. 4231. As to the sound pressure, its continuous A-weighted equivalent level, $\mathrm{L}_{\mathrm{eq}}(\mathrm{A})$, was measured. The data underwent analysis in frequency bands in 1/3-octaves in the range $20 \mathrm{~Hz}-20 \mathrm{kHz}$. Before and after the tests, the deviations from the initial calibration value have been verified by means of the calibrator. The sampling time was $30 \mathrm{~s}$ and each measurement was replicated at least three times.

The net noise reduction effect, named attenuation, was obtained by difference between the noise measured over open ground and the values obtained in presence of the hedges, at the same distance between noise source and microphone (Fang and Ling, 2005). The differences of the means were tested by an analysis of variance (ANOVA), considering a block design corresponding to the sampling distances. The Tukey test was used for multiple comparisons among treatments statistically significant. The statistical analyses were computed with the software R (R Core Team, 2013).

\section{Experimental design}

Figure 1 shows the scheme of sampling. In the trials T1, T2 and $\mathrm{T} 3$, the noise measurements were taken placing the noise source at 1,2 and $5 \mathrm{~m}$ from the hedge and the microphone, on the other side, at the same distances. In such a way it was obtained a total of $9(3 \times 3)$ points of measurement at 6 relative distances between source and microphone (2, 3, 4, 6, 7 and $10 \mathrm{~m})$. Both microphone and noise source were placed at $0.8 \mathrm{~m}$ of height from the ground.

Table 1. Basic properties of different trials performed.

\begin{tabular}{|c|c|c|c|c|c|c|c|c|}
\hline Trial & $\begin{array}{c}\text { Air } \\
\text { temperature } \\
{\left[{ }^{\circ} \mathrm{C}\right]}\end{array}$ & $\begin{array}{l}\text { Noise } \\
\text { source }\end{array}$ & $\begin{array}{l}\text { Hedge } \\
\text { species }\end{array}$ & $\begin{array}{l}\text { Hedge size } \\
\text { (depth) } \\
\text { [m] }\end{array}$ & $\begin{array}{c}\text { Hedge size } \\
\text { (height) } \\
\text { [m] }\end{array}$ & $\begin{array}{c}\text { Hedge optical } \\
\text { porosity } \\
{[\%]}\end{array}$ & $\begin{array}{c}\text { Distances of } \\
\text { microphone from } \\
\text { the hedge [m] }\end{array}$ & $\begin{array}{l}\text { Distances of } \\
\text { source from } \\
\text { the hedge [m] }\end{array}$ \\
\hline \multirow[t]{2}{*}{$\mathrm{T} 1$} & \multirow[t]{2}{*}{16} & \multirow{2}{*}{$\begin{array}{l}\text { - Brush-cutter } \\
\text { in the field side }\end{array}$} & \multirow[t]{2}{*}{ P. laurocerasus } & 1.20 & \multirow[t]{2}{*}{2.10} & 1.5 & \multirow[t]{2}{*}{$1,2,5$} & \multirow[t]{2}{*}{$1,2,5$} \\
\hline & & & & 1.90 & & 0.5 & & \\
\hline T2 & 16 & $\begin{array}{l}\text { - Brush-cutter } \\
\text { in the parking side }\end{array}$ & P. laurocerasus & $\begin{array}{l}1.20 \\
1.90\end{array}$ & 2.10 & $\begin{array}{l}1.5 \\
0.5\end{array}$ & $1,2,5$ & $1,2,5$ \\
\hline T3 & 26 & - Brush-cutter & L. nobilis & $\begin{array}{l}0.40 \\
0.85 \\
1.20 \\
1.65\end{array}$ & 2.40 & $\begin{array}{l}14.3 \\
4.6 \\
1.4 \\
0.7\end{array}$ & $1,2,5$ & $1,2,5$ \\
\hline T4 & 27 & - Air conditioning plant & L. nobilis & $\begin{array}{l}0.40 \\
0.85 \\
1.20 \\
1.65\end{array}$ & 2.40 & $\begin{array}{l}14.3 \\
4.6 \\
1.4 \\
0.7\end{array}$ & $1,2,5$ & 1 \\
\hline
\end{tabular}


In the trial $\mathrm{T} 4$, the receiver was placed in front of the noise source (air conditioning plant) at 1, 2 and $5 \mathrm{~m}$ of distance, interposing barriers formed by 1, 2, 3 and 4 rows of Laurel. The microphone was set on a tripod at a height of $0.8 \mathrm{~m}$ from the ground.

Measurements at the same distances were made as well over open ground, without hedge.

The ground surface was gravel on both sides in the trial T3 (carried out with Laurel plants), gravel road and asphalt in the trials T1 and T2 (with the Cherry Laurel hedge) and meadow of spontaneous grass of about $4-5 \mathrm{~cm}$ of height in trial T4. To separate the effect of ground surface on noise, a statistical analysis (ANOVA) was carried out on the data of the trial T1 and T2, considering the side of noise measurement (parking or field) as an additional factor of variation. During the trials, the micrometeorological conditions were constantly monitored by means of a Kestrel mod. 4500 portable meteo-station. No tests were carried out with wind speed exceeding $1.7 \mathrm{~m} \mathrm{~s}^{-1}$.

\section{Results}

Figure 2 shows the sound spectra (measured at $3.0 \mathrm{~m}$ of distance from the source, over open ground) of the two employed noise sources, the air conditioning plant and the brush-cutter. In average, the air conditioning plant emitted a noise of $54.9 \mathrm{~dB}(\mathrm{~A})$
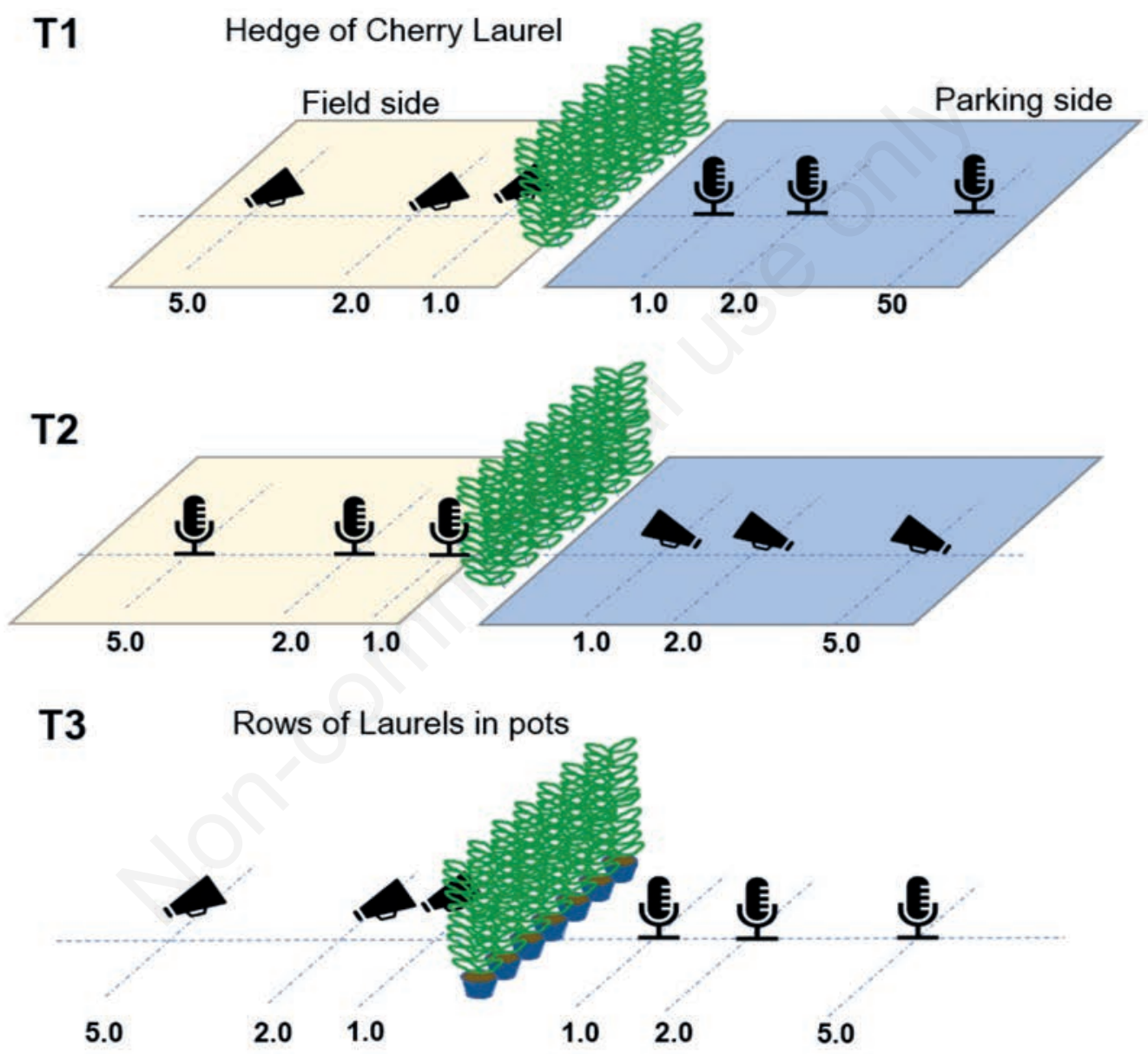

T4

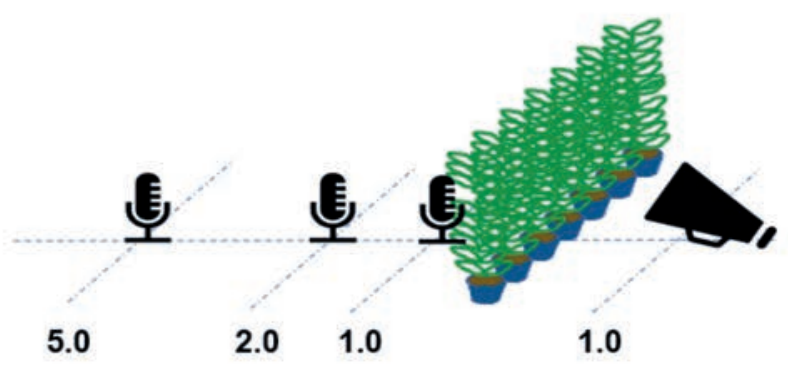

Figure 1. Scheme of trials design, with the distances $(\mathrm{m})$ between noise source (symbol: horn speaker) and receiver (symbol: microphone). T1, T2, T3 and T4 refer to the trials. 
$( \pm 0.3 \mathrm{~dB}(\mathrm{~A}))$, while the brush-cutter attained an average of 91.9 $\mathrm{dB}(\mathrm{A})( \pm 0.5 \mathrm{~dB}(\mathrm{~A}))$. The spectra showed different sound characteristics, with a prevalence of high sound frequencies (greater than $2 \mathrm{kHz}$ ) for the brush-cutter, whereas the air conditioning plant shows values of sound level pressure forming a bell-shaped curve, with a decreasing trend at frequencies higher than $1000 \mathrm{~Hz}$.

\section{Trials $\mathrm{T} 1$ and $\mathrm{T} 2$}

In the trial with the natural hedge of Cherry Laurel as barrier and the brush-cutter as noise source, an ANOVA was firstly performed to analyse the influence of the ground surface, which was different behind and in front of the hedge. When the source of noise was placed in the side with paved surface, the average sound pressure level resulted slightly higher $(86.0 \mathrm{~dB}(\mathrm{~A}))$ than when it was in the side with gravel surface $(85.7 \mathrm{~dB}(\mathrm{~A}))$. Since this difference resulted significant after the ANOVA (probability $>\mathrm{F}=$ 0.0012 ), the results referred to each condition were analysed separately (trials $\mathrm{T} 1$ and $\mathrm{T} 2$, respectively).

In both trials, the hedge provided a significant reduction of the average noise pressure $(\mathrm{dB}(\mathrm{A}))$. The hedge size reduction due to the pruning (optical porosity increase: $0.5 \%$ to $1.5 \%$ ) did not affect the average noise attenuation (Figure 3).

The ANOVA shows also a significant effect due to the relative positions of noise source and receiver (microphone). In fact, the interaction of the two factors resulted significant during both trials. The Figure 4 shows the results of noise measurements in $\mathrm{T} 1$ and T2. The maximum average noise attenuation $(2.7 \mathrm{~dB}(\mathrm{~A}))$ was
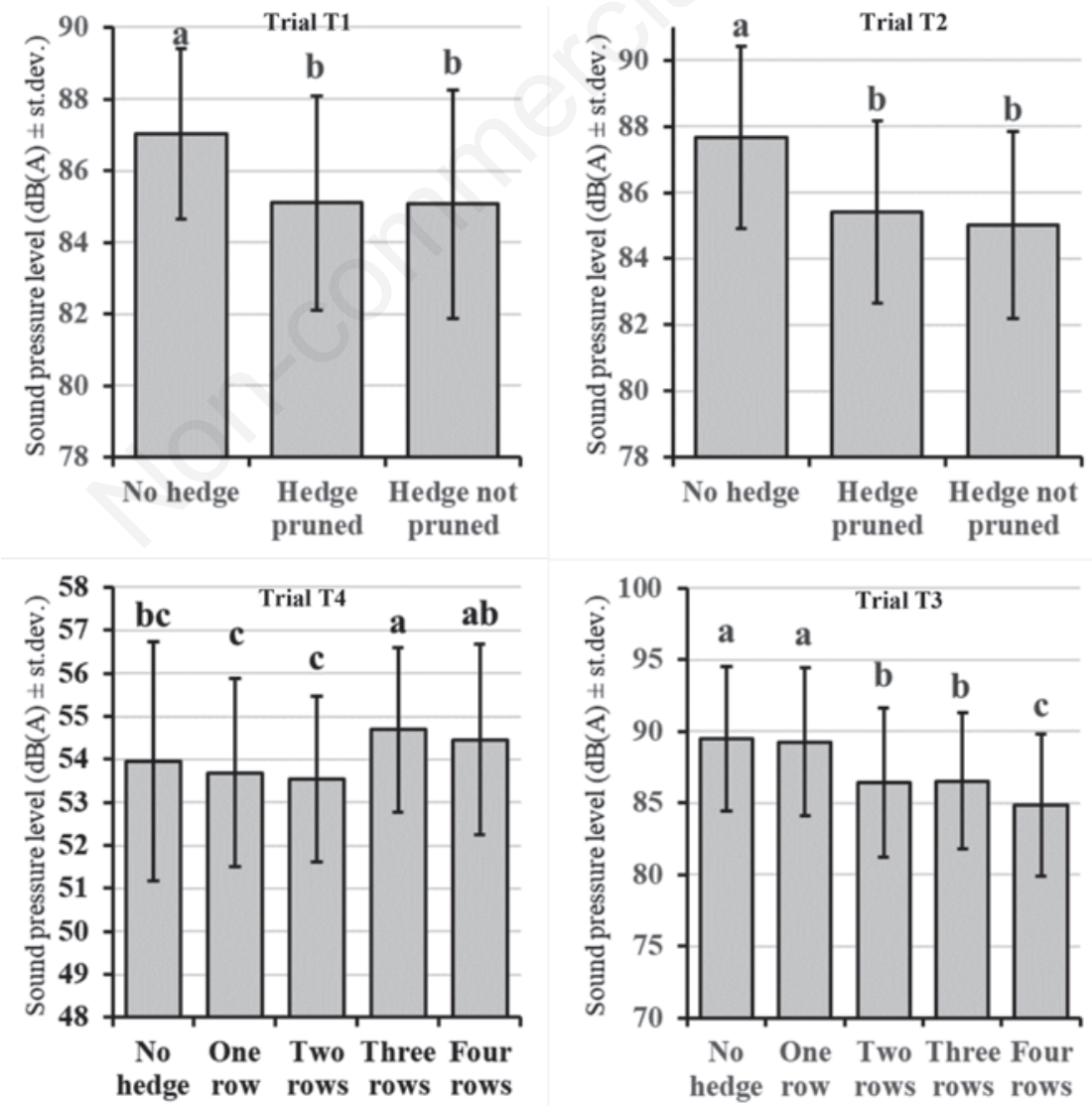

obtained when the relative distance between noise source and receiver was equal to $3 \mathrm{~m}$, with microphone at $2 \mathrm{~m}$ from the hedge and noise source at $1 \mathrm{~m}$ (Figure 4).

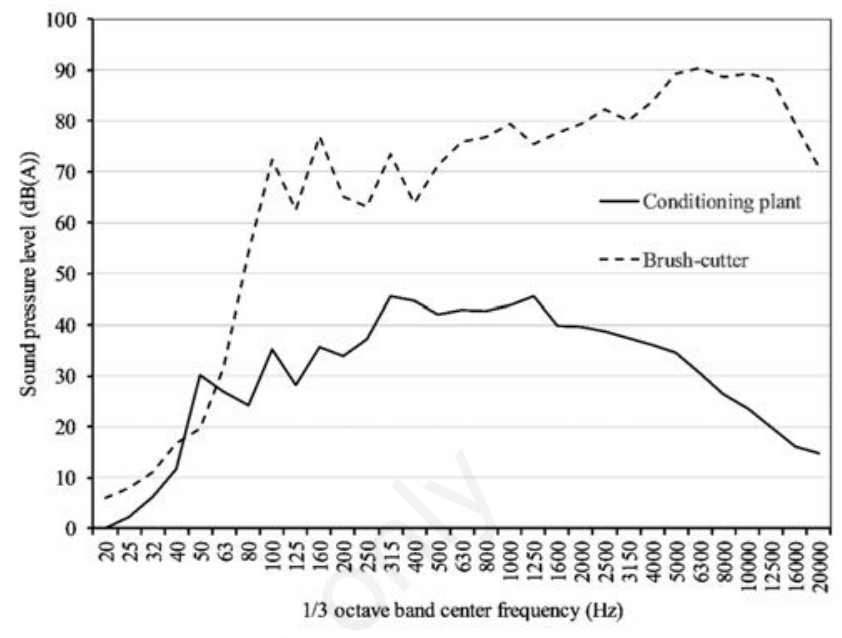

Figure 2. Spectra of frequencies (1/3 octave band) of the two noise sources employed in the trials. The sound pressure level $(\mathrm{dB}(\mathrm{A}))$ was measured at $3.0 \mathrm{~m}$ of distance, over open ground.

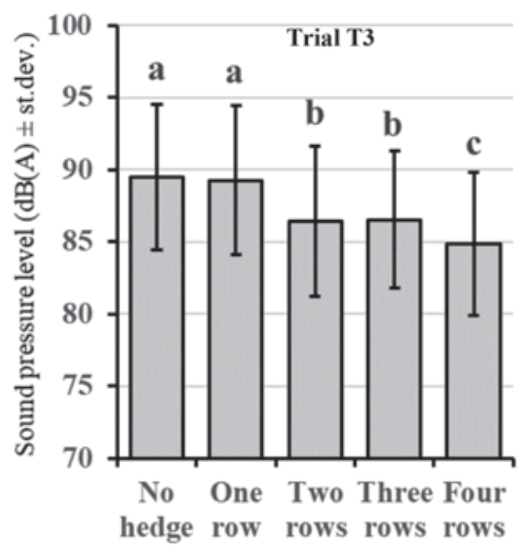

Figure 3. Average sound pressure level in the four trials (from 1 to 4 clockwise). Means denoted by the same letter are not significantly different at the $5 \%$ level of probability after a Tukey test. 
The sound spectra (Figure 5A and B) show that, in both cases, the strongest attenuation of the sound level occurred at high frequencies, higher than $1600 \mathrm{~Hz}$. This effect was particularly clear for the hedge not pruned. Moreover, when the noise source was placed in the field side (with a gravel ground surface) some attenuation was showed also in the frequencies between 125 and 250 $\mathrm{Hz}$, especially by the pruned hedge.

\section{Trial T3}

This trial (brush-cutter as source of noise and the Laurels grown in containers as hedge) evidenced a significant noise reduction caused by the hedge depending on the hedge size. No statistical difference was observed interposing only a row of plants (porosity $14.3 \%$ ), while when the barrier was formed by two rows (porosity $4.6 \%$ ) the noise attenuation was significant. An additional row of plants (porosity $1.4 \%$ ) did not significantly increase the average attenuation, while the maximum attenuation $(4.6 \mathrm{~dB}(\mathrm{~A}))$, as average of all points of measurement) was obtained with the hedge formed by four rows of plants (porosity $0.4 \%$ ) (Figure 3 ).

Like in the case of the trials with Cherry Laurel, the analysis of the sound spectra showed that the maximum level of attenuation was obtained in the high frequency range $(>2000 \mathrm{~Hz})$. Minor attenuations occurred between 200 and $630 \mathrm{~Hz}$, whereas there was no effect around $800 \mathrm{~Hz}$ (Figure 6A).

\section{Trial T4}

In the fourth trial the noise source was the air conditioning plant and the hedge was formed by rows of Laurel plants grown in containers.

As a general result, the hedges did not reduce the noise produced by the source.

The ANOVA results show a statistically significant difference among the different tested hedges, but this result is not related to the size of the hedges. For example, utilising a three-rows hedge, the noise level measured is greater than the noise recorded without barrier.

Figure $6 \mathrm{~B}$ reports the attenuation values, showing no relation between the presence of the hedges and the noise reduction. In some cases, the hedges incited even an increment of the noise [up to $5.5 \mathrm{~dB}(\mathrm{~A})$ with the four rows hedge around $6.3 \mathrm{kHz}$ ].

Figure 7 shows the average attenuations obtained in the trial with the most effective hedge (four rows of Laurel plants) depending on the relative position of the noise source and the receiver. The maximum attenuations were obtained when the noise source was placed at $2 \mathrm{~m}$ from the hedge and the microphone at $1 \mathrm{~m}$ and when both the source and the microphone were placed at $5 \mathrm{~m}$ from the hedge.

\section{Discussion}

In this study, two common evergreen shrubs, L. nobilis and $P$. laurocerasus, were tested as noise barriers. The selected sources of noise were characterised by clearly different sound spectra, in terms of both equivalent level of sound pressure $(\mathrm{dB}(\mathrm{A}))$ and frequency $(\mathrm{Hz})$. The study also aimed at providing practical results taking in account real situations, since the studied noise sources are present in urban areas, beside they show different intensity of occurrence and duration of noise emission.

The different parts of the plants differently act in noise filtering. For example, leaves and twigs can reduce the level of sound with higher energy, like those characterised by predominance of

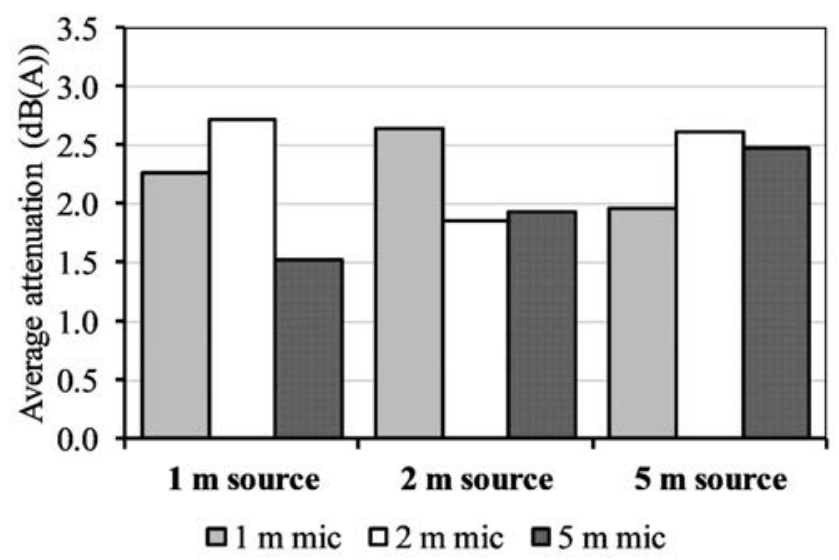

Figure 4. Average attenuation $(\mathrm{dB}(\mathrm{A}))$ by positions of noise source and microphone. Average of trials T1 and T2 and of the two hedge configurations.

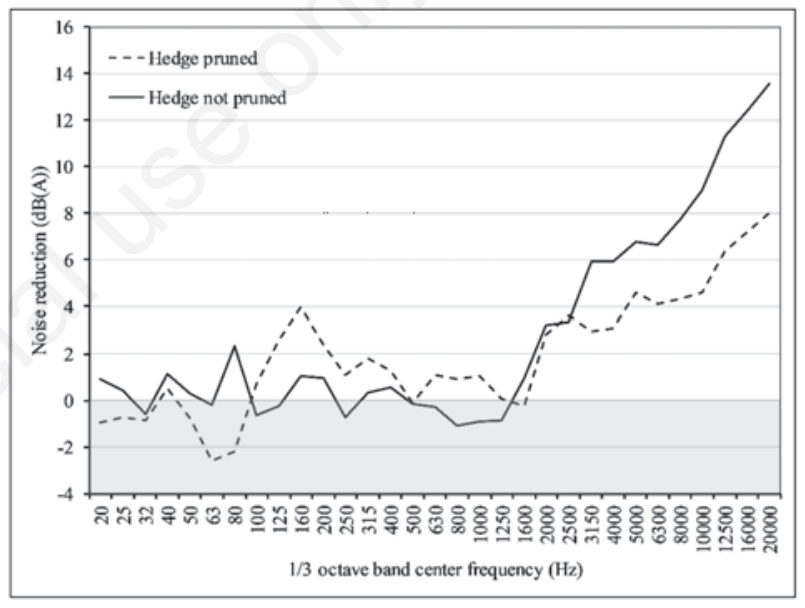

A

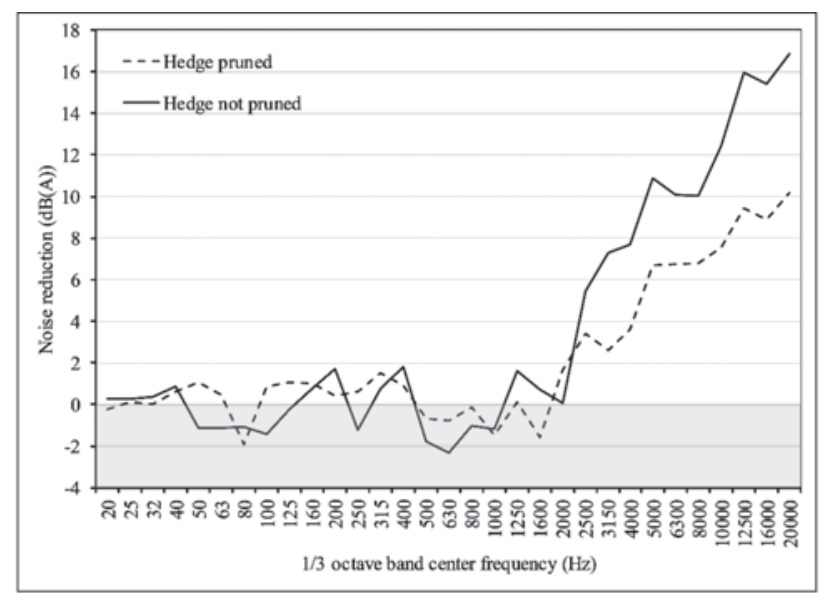

B

Figure 5. A) Average noise reduction $(\mathrm{dB}(\mathrm{A}))$ by frequency $(1 / 3$ octaves band), caused by the hedges of Cherry Laurel with brush cutter as noise source, placed in the gravel road. B) Average noise redution $(\mathrm{dB}(\mathrm{A}))$ by frequency $(1 / 3$-octaves band), caused by the hedges of Cherry Laurel with brush cutter as noise source, placed in the parking in asphalt. 
the high frequencies, while low frequencies tend to be filtered by trunks and wood. In this work, when a barrier formed by rows of Laurel is interposed between noise source and receiver, the attenuation caused by the plants was negligible or absent in the fourth trial, where the noise source was the air conditioning plant, and the noise was characterised by predominant frequencies in the interval $100-1600 \mathrm{~Hz}$ (Figure 2), below the interval in which the tested hedges resulted effective in reducing the noise emitted by the brush-cutter $(f>1600)$. Consequently, in the trial T4, it can be assumed that the planting of a hedge around the air conditioning plant will improve the visual and aesthetic value of our garden but will not have practical responses about noise attenuation. In this situation, it is likely that a hedge having a greater presence of woody parts could reduce the noise better than the tested one.

In the trials T1 and T2, an existing hedge of Cherry Laurel was tested for its capability to reduce noise. This hedge was placed between the white road surrounding a field (with a gravel ground surface) and a parking lot, with the ground surface of asphalt. In

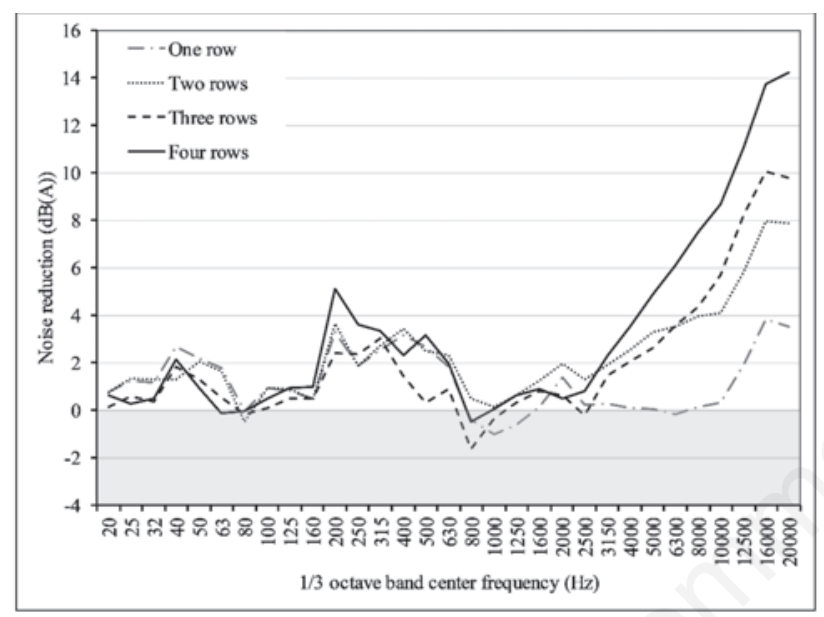

A

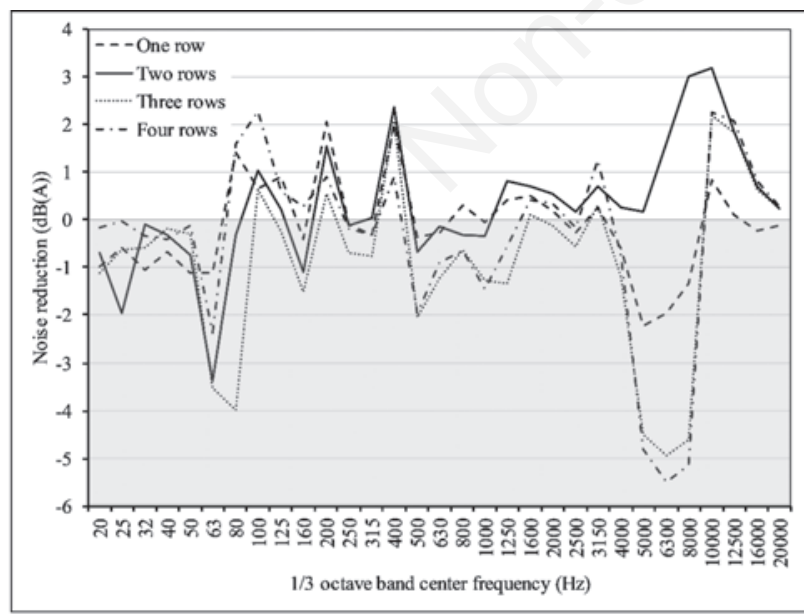

B

Figure 6. A) Average noise reduction $(\mathrm{dB}(\mathrm{A}))$ by frequency $(1 / 3-$ octaves band), caused by the hedges of Laurels with brush-cutter as noise source (trial T3). B) Average noise reducion ( $\mathrm{dB}(\mathrm{A})$ ) by frequency (1/3-octaves band), caused by the hedges of Laurel with conditioning plant as noise source (T4). this case, depending on the side where the noise was recorded, the noise propagation was different. Therefore, the attenuation incited by the hedge was slightly influenced by the ground surface. Placing the noise source on asphalt caused an increase in the noise level recorded behind the hedge, while the attenuation caused by the hedge was greater when the noise came from the field side. This effect, likely determined by the destructive interference of sound waves reflected by the softer surface (Bucur, 2006), can be observed in the Figures $5 \mathrm{~A}$ and $6 \mathrm{~A}$ where, in the frequency intervals $125-800 \mathrm{~Hz}$ and $200-800 \mathrm{~Hz}$, respectively, several peaks of attenuation occur when the noise source is on the gravel road.

To obtain a significant result of noise attenuation it seems that vegetation density should be at least $4.6 \%$ in terms of light porosity, but the best results are obtained with a porosity under $0.7 \%$.

The noise attenuation due to the Laurel and Cherry Laurel hedges generally increases with the frequency and is particularly effective in the interval 2000-20,000 Hz (Figures 5 and 6A), confirming the data reported by different authors (Pal et al., 2000; Tyagi et al., 2006).

The magnitude of the attenuation also depended on the relative distances and positions of the hedge, of the noise source and of the microphone. This effect was evaluated in the trials T1, T2 and T3, where combining the various positions of source and receiver referred to the hedge, provided 9 different configurations (Figure 1). For example, the $3 \mathrm{~m}$ distance between source and receiver, was obtained either placing the microphone at $1 \mathrm{~m}$ and the source at 2 $\mathrm{m}$ from the hedge or, vice-versa, placing the microphone at $2 \mathrm{~m}$ and the source at $1 \mathrm{~m}$ from the hedge. A similar situation also occurred for the distances of 6 and $7 \mathrm{~m}$. In this range of distances, the noise attenuation seemed to be slightly higher when the noise source was more distant from the hedge than the microphone. Observing the cases in the trial T3, the same maximum attenuation was obtained with the source at $2 \mathrm{~m}$ and the microphone at $1 \mathrm{~m}$ from the hedge and with both source and receiver at $5 \mathrm{~m}$ from the hedge. In the first case, when the microphone and the noise source are near the hedge, the shield function of the latter is dominant on the propagation of sound waves. Increasing the distance between noise source and hedge, the noise is increasingly capable to overrule the hedge and reach the microphone, especially if the latter also is moving away from the hedge. In this situation, the sound waves may be reflected by vegetation and by the surface leading a

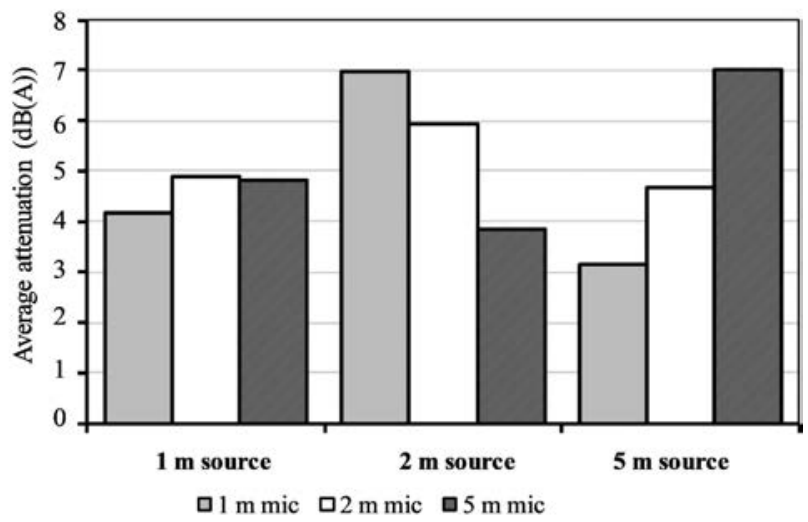

Figure 7. Average attenuation $(\mathrm{dB}(\mathrm{A}))$ by positions of noise source and microphone. Values obtained with the four rows Laurel hedge. 
sort of bridge effect with a relative reduction of the noise attenuation effect. Moreover, part of the sound waves could reach the microphone after having outflanked the hedge, favoured by its contained length.

\section{Conclusions}

The use of hedges as noise reducing barriers is an interesting nature-based strategy for urban sustainability. Hedges can be easily planted and grown either close to the noise source or close to the receiver, to optimise noise attenuation effect. A wide range of plant species, different for morphological and vegetative characteristics is available, allowing urban designers to appropriate choices, regarding, for example, their habitus (if evergreen or deciduous).

This paper has confirmed that hedges having a dense vegetation (that results in a low light porosity) can reduce noise pollution even if they are rather small.

The observed attenuations particularly regarded the higher frequencies, both with $L$. nobilis and P. laurocerasus, while no effect was recorded against the conditioning plant's emissions characterised by low frequencies and low sound pressure levels.

The noise attenuation caused by the hedges studied, rarely achieved great values in terms of magnitude, but their utilisation in urban areas should be evaluated considering the numerous ecological services that hedges can provide to ameliorate the urban environment and the well-being. Further studies will lead to an optimisation of hedges efficiency against noise pollution as a result of an accurate activity of designing or planning gardens and urban green areas, based on the choice of the most suitable species and of the shape, dimensions and position of the hedges, depending on the prevailing noise source in each area taken into consideration. Their utilisation in urban areas should be improved also considering the numerous ecological services they can provide to ameliorate the urban environment and the well-being.

\section{References}

Alvey A.A. 2006. Promoting and preserving biodiversity in the urban forest. Urban Forest. Urban Green. 5:195-201.

Bolund P., Hunhammar S. 1999. Ecosystem services in urban areas. Ecol. Econ. 29:293-301.

Bowler D.E., Buyung-Ali L., Knight T.M., Pullin A.S. 2010. Urban greening to cool towns and cities: a systematic review of the empirical evidence. Landscape Urban Plan. 97:147-55.

Bucur V. 2006. Traffic noise abatement. In: Urban forest acoustics. Springer, Berlin, Heidelberg, Germany.

Ciammaichella I., Ferrario P., Pessina D., Toccolini A. 2005. Riduzione del rumore da traffico veicolare con barriere vegetali [Traffic noise reduction by using natural (soil and vegetation) barriers]. Riv. Ing. Agr. 1:25-33.

Erbino C., Toccolini A., Vagge I., Ferrario P.S. 2015. Guidelines for the design of a healing garden for the rehabilitation of psychiatric patients. J. Agric. Engine. 46:43-51.

Escobedo F.J., Kroeger T., Wagner J.E. 2011. Urban forests and pollution mitigation: Analysing ecosystem services and disservices. Environ. Pollut. 159:2078-87.

European Environment Agency (EEA). 2017. Managing exposure to noise in Europe. EEA BRIEFING 01/2017. pp 1-4.

Fang C.F., Ling D.L. 2003. Investigation of the noise reduction provided by tree belts. Landscape Urban Plan. 63:187-95.

Fang C.F., Ling D.L. 2005. Guidance for noise reduction provided by tree belts. Landscape Urban Plan. 71:29-34.

Federer C.A. 1976. Trees modify the urban microclimate. J. Arboricult. 2:121-7.

Gratani L., Varone L. 2013. Carbon sequestration and noise attenuation provided by hedges in Rome: the contribution of hedge traits in decreasing pollution levels. Atmos. Pollut. Res. 4:315-22.

Islam M.N., Rahman K.S., Bahar M.M., Habib M.A., Ando K., Hattori N. 2012. Pollution attenuation by roadside greenbelt in and around urban areas. Urban Forest. Urban Green. 11:460-4.

Kragh J. 1981. Road traffic noise attenuation by belts of trees. J. Sound Vibrat. 74:235-41.

Maleki K., Hosseini S.M., Nasiri P. 2010. The effect of pure and mixed plantations of Robinia pseudoacacia and Pinus eldarica on traffic noise decrease. Int. J. Environ. Sci. 1:213-24.

Mori J., Hanslin H.M., Burchi G., Sæbø A. 2015. Particulate matter and element accumulation on coniferous trees at different distances from a highway. Urban Forest. Urban Green. 14:170-7.

Nowak D.J., Crane D.E., Stevens J.C. 2006. Air pollution removal by urban trees and shrubs in the United States. Urban Forest. Urban Green. 4:115-23.

Ow L.F., Ghosh S. 2017. Urban cities and road traffic noise: reduction through vegetation. Appli. Acoust. 120:15-20.

Pal A.K., Kumar V., Saxena N.C. 2000. Noise Attenuation by Green Belts. J. Sound Vibrat. 234:149-65.

R Core Team, 2013. R: a Language and Environment for Statistical Computing. R Foundation for Statistical Computing, Vienna, Austria. Available from: www.R-project.org

Schneider C.A., Rasband W.S., Eliceiri K.W. 2012. NIH Image to ImageJ: 25 years of image analysis. Nat. Methods 9:671-75.

Tyagi V., Kumar K., Jain V.K. 2006. A study of the spectral characteristics of traffic noise attenuation by vegetation belts in Delhi. Appl. Acoust. 67:926-35.

Van Renterghem T. 2018. Towards explaining the positive effect of vegetation on the perception of environmental noise. Urban Forest. Urban Green. [Epub ahead of print].

Van Renterghem T., Attenborough K., Maennel M., Defrance J., Horoshenkov K., Kang J., Bashir I., Taherzadeh S., Altreuther B., Khan A., Smyrnova Y., Yang H.S. 2014. Measured light vehicle noise reduction by hedges. Appl. Acoust. 78:19-27.

Van Renterghem T., Botteldooren D., Verheyen K. 2012. Road traffic noise shielding by vegetation belts of limited depth. J. Sound Vibration 331:2404-25.

Viollon S, Lavandier C, Drake C. 2002. Influence of visual setting on sound ratings in an urban environment. Appl. Acoust. 63:493-511.

Yang F., Bao Z.Y., Zhu Z.J., 2011. An assessment of physiological noise reduction by landscape plants. Int. J. Environ. Res. Public Health 8:1032-48. 